\title{
Adults on the Autism Spectrum Face Significant Challenges Accessing Health Care Services
}

\author{
Setareh Ghahari ${ }^{1}$, Megan Widmer ${ }^{1}$, Tom Heneghan ${ }^{1}$, Methuna Naganathan ${ }^{1} \&$ Thanusha Kathiravel ${ }^{1}$ \\ ${ }^{1}$ School of Rehabilitation Therapy, Queen's University, Kingston, Ontario, Canada \\ Correspondence: Setareh Ghahari, School of Rehabilitation Therapy, Queen's University, 31 George Street, \\ Kingston, Ontario, K7L 3N6, Canada. Tel: 1-613-533-6789 ext.36789. E-mail: setareh.ghahari@queensu.ca
}

Received: August 26, 2021 Accepted: November 26, 2021 Online Published: December 10, 2021

doi:10.5539/gjhs.v14n1p53 URL: https://doi.org/10.5539/gjhs.v14n1p53

\begin{abstract}
Autism Spectrum Disorder (ASD) is a neurodevelopmental condition characterized by difficulties with social skills, verbal and non-verbal communication, repetitive behaviours and atypical sensory processing. Individuals on the autism spectrum face a higher prevalence of health conditions and have a higher mortality rate than the general population. There is a critical need to understand adults' experiences on the autism spectrum when accessing health care services to understand how to improve accessibility to health care for these individuals. The purpose of this scoping review was to investigate how adults on the autism spectrum access and experience health care services. Four databases, including Embase, MEDLINE, CINAHL, and PsycInfo, were systematically searched for literature exploring how individuals on the autism spectrum access and experience health care. Results were extracted and categorized into five determinants based on the accessibility framework described by Levesque et al. (2013). Results indicated adults on the autism spectrum experience numerous barriers when accessing health care services. The dimension of access most frequently cited was the appropriateness of care, followed by the acceptability of care. It is essential to explore access as it is often conceptualized as the availability and affordability of services; however, results of this study indicate the broader experience of quality care provision and acceptance of the individual are important in understanding the complex experience individuals on the autism spectrum face. Based on these findings, there is a need to provide comprehensive education and clinical practice guidelines for health care providers to help reduce barriers to providing appropriate care for adults on the autism spectrum. Efforts to destigmatize intrapersonal and extra-personal perceptions of individuals on the autism spectrum will help overcome the barriers that affect care acceptability. Further research must understand how to design and implement strategies to maximize health service access for adults on the autism spectrum.
\end{abstract}

Keywords: adult, autism, access, health care, services

\section{Introduction}

Autism Spectrum Disorder (ASD) is a neurodevelopmental condition characterized by difficulties with social skills, verbal and nonverbal communication, repetitive behaviors and atypical sensory processing (American Psychiatric Association, 2013). It is estimated that one in 160 children worldwide has an autism diagnosis (World Health Organization, 2018), with the prevalence continuing to increase globally. Historically, individuals were typically diagnosed with ASD as a child. However, data from many countries has shown there is an increasing population of individuals diagnosed with ASD in adulthood (Bachmann et al., 2018; Diallo et al., 2018; Jensen et al., 2014; Schendel \& Thorsteinsson, 2018). For example, Jensen et al. (2014) studied the incidence rates of ASD across the lifespan from 1995 to 2010. During this lifespan, the incidence rates for ASD increased from 9.0 to 38.6 per 100,000 persons (Jensen et al., 2014). This increase was very evident in the adult population (Jensen et al., 2014).

Compared to the general population, individuals on the autism spectrum have poorer life outcomes, including reduced education and employment opportunities, fewer social networks and supports, and a lower quality of life (Baldwin et al., 2014; Hewitt et al., 2012; Nord et al., 2016; van Asselt-Goverts et al., 2015; van Hees et al., 2015). Alongside these poor life outcomes, research has consistently shown that individuals on the autism spectrum also have a higher prevalence of health conditions than the general population (Fortuna et al., 2016). Conditions including seizure disorders, hypertension, diabetes, obesity, gastrointestinal issues, immune issues, sleep disorders and genetic disorders, among others, disproportionately affect individuals on the autism spectrum (Croen et al., 
2015; Fortuna et al., 2016). Mental health or psychiatric conditions including depression, anxiety, obsessive-compulsive disorder, schizophrenia, opposition defiance disorder, bipolar disorder are also more frequently observed in individuals on the autism spectrum (Croen et al., 2015; Fortuna et al., 2016; Hirvikoski et al., 2016; Mattila et al., 2010). Of note, this paper will use 'person-first' language when referring to individuals on the autism spectrum, however, the authors acknowledge that there is an ongoing discussion regarding the appropriate use of language amongst the Autism community.

Cumulatively, the presence of co-occurring physical and mental health conditions means that many individuals on the autism spectrum die prematurely. Mortality rates among individuals on the autism spectrum are significantly higher than that of the general population. For example, individuals on the autism spectrum die on average 16.33 years earlier than their typically developing counterparts (Hirvikoski et al., 2016). Furthermore, the risk of mortality is two times higher for the individuals on the autism spectrum than individuals who are not on the autism spectrum (Jokiranta-Olkoniemi et al., 2020).

Ensuring that individuals on the autism spectrum have adequate access to health care services is, therefore, of utmost importance. Indeed, the right to quality, available and accessible health care has been recognized as a human right by the World Health Organization (World Health Organization, 2017). While parents can support their children to access health care, individuals on the autism spectrum must access health care independently as individuals age into adolescence and adulthood. For adults on the autism spectrum, the social-communicative difficulties experienced may pose significant barriers to accessing and navigating the health care system.

Access to health care can be defined as an opportunity to identify health care needs, seek or use healthcare services, and have needs met through services (Levesque et al., 2013). Accessibility can be conceptualized into five dimensions, including approachability, acceptability, availability, affordability, and appropriateness (Levesque et al., 2013). Table 1 presents the definition of the five dimensions of access to health services. Research has consistently shown the importance of accessible health care services, with accessible health care services including factors such as respect towards patients, appointment reminders, sufficient time to meet with health care professionals, consistent health care provider hours, interprofessional care, culturally sensitive health care providers and more (Bogenschutz, 2014; Ross et al., 2015).

Table 1. Levesque et al. (2013) definition of dimensions of access to health services

\section{Appropriateness}

The fit between services offered and client needs includes the timeliness of the service, the amount of care spent in assessing and determining the correct treatment for each unique care need, and the technical and interpersonal quality of the services provided.

\section{Acceptability}

Cultural and social factors determining the possibility for people to accept the service and the judged appropriateness for the person to seek care.

\section{Availability}

The physical places of health services and health care providers and ability to reach both in a physically and in a timely manner.

\section{Affordability}

The economic capacity for people to spend resources and time on appropriate services, including the capacity to generate resources to pay for care.

\footnotetext{
Approachability

Transparency that allows potential clients to identify available services, to identify how to contact the available services, and to understand the impact the available services would have on their health.
}

There is a vast array of existing literature related to the experience and accessibility of health care services among children on the autism spectrum, their families, and adolescents transitioning from childhood to adulthood. Many existing clinical practice guidelines ensure that families with children on the autism spectrum can navigate through the health care system (Murphy et al., 2016). However, there is a lack of literature regarding individuals' experience on the autism spectrum when accessing health care services when they reach adulthood. A recent systematic review by Mason et al. in 2019 focused on the physical aspect of accessing health services for Autistic adults. They included six papers (two qualitative, two quantitative and two mixed methods studies) in their review. 
The main findings from this study were significant challenges in communication between patients and providers, sensory sensitivity that results in anxiety before and during encounters, and barriers resulting from impairments in executive functioning and planning. The findings touch on all areas of access as defined by Levesque et al. (2013) but not on the acceptability and affordability of the services.

Therefore, the purpose of this study was to investigate the barriers adults on the autism spectrum experience when accessing health care services, according to Levesque et al.'s (2013) framework of accessibility. This literature review uses Levesque et al.'s (2013) framework of accessibility which acknowledges the social determinants of health of individuals on the Autism spectrum. This framework includes five corresponding dimensions of abilities (i.e. Ability to perceive; Ability to seek; Ability to reach; Ability to pay; and Ability to engage) (Levesque et al., 2013) that allow for the investigation of barriers as a result of the dimensions of abilities (Corscadden et al., 2017).

\section{Methods}

\subsection{Design}

This review adhered to the scoping review approach set out by Arksey and O'Malley (2005). The search strategy was an iterative process to best answer the question: "How do adults on the autism spectrum access and experience health care services?"

\subsection{Search Strategy}

Search terms included but were not limited to "Autism", "health service", "health care system", "access", "availability", and "health care disparities." These words and phrases were truncated and used with various pertinent connecting terms such as and/or to construct the search strategy. No filters or restrictions were applied to the year of publication.

The search was conducted using Embase, MEDLINE, CINAHL, and PyscINFO, as each database contains a breadth of information concerning health, health services, and health provision. A manual search of relevant studies' references was conducted to ensure the saturation of pertinent articles.

\subsection{Study Selection}

Publications of interest were peer-reviewed published articles that explored access and health care experiences of individuals on the autism spectrum. Studies were included if 1) all participants were above the age of 18 and had been formally or self-diagnosed with ASD, 2) the article pertained to health care services or 3) explored the perceptions of caregivers and health care professionals connected to adults accessing health care service.

Studies were excluded if the sample population was defined as individuals with an "intellectual or developmental disability" without the provision of ASD-specific data. This decision was made because intellectual and developmental disabilities encompass a broad range of conditions that may not apply to the experience of adults on the autism spectrum. Research related solely to the cost burden on systems such as hospitals, governments, and insurance companies was excluded as they did not address person-level interaction with health care services. Research related to the transition from pediatric to adult service use was also excluded because the period was deemed significantly different and unique from the typical adult experience when accessing health care services.

\subsection{Data Extraction}

Studies were imported to a reference manager (EndNote) and then into a review manager (Covidence), where duplicates were removed. Three authors worked independently to review and select article titles and abstracts that met the inclusion criteria. The other two authors reviewed articles selected by one author to ensure agreement of selected articles. Three authors conducted a full-text review of the articles independently to ensure the inclusion criteria were met: Information about design, population, purpose, findings related to the experience of access, and implications was extracted from relevant articles (see Table 2). Once data had been extracted from articles, common themes such as "provider knowledge", "communication barriers," or "inadequate service for needs" were generated by the three authors together (see Table 3). Levesque et al.'s (2013) framework of accessibility was then used to categorize the themes into five different dimensions: appropriateness, approachability, availability, affordability, and acceptability (see Table 1 and Table 2). This framework was used as it consists of a cumulative perspective of access, has been referenced and utilized extensively in health literature, and is client-centred based on the obstacles experienced by individuals (Levesque et al., 2013). A secondary database search was performed one year following the initial search. Selected articles were screened against inclusion and exclusion criteria. Findings from the relevant articles were extracted and contributed to the findings detailed in this paper. Three authors worked together to extract themes from papers and sort them into the dimensions of access to ensure the themes' consistency and authenticity. 
Table 2. Summary of all papers included in the scoping review

\begin{tabular}{|c|c|c|c|c|c|}
\hline Citation & Study Design & Sample \& Sample Size & Age of Sample & Country & Objective \\
\hline $\begin{array}{l}\text { Dudley, Klinger, } \\
\text { Meyer, Powell, \& } \\
\text { Klinger, } 2019\end{array}$ & $\begin{array}{l}\text { Quantitative } \\
\text { Survey (online, mail) }\end{array}$ & $\begin{array}{l}\text { Caregivers on behalf of } \\
\text { individuals on the autism } \\
\text { spectrum: } \mathrm{n}=274\end{array}$ & $\begin{array}{l}20-58 \\
\text { Mean: } 35.4 \\
\text { SD: } 6.5\end{array}$ & USA & $\begin{array}{l}\text { To investigate service use, unmet } \\
\text { needs, and obstacles to service } \\
\text { access }\end{array}$ \\
\hline
\end{tabular}

riers to Access \&

\section{Subthemes}

Availability: Lack of or cost of

transportation

Affordability: Living situations

lead to less funding

Approachability: Unsure of

where to find or unaware of

services

\begin{tabular}{|c|c|c|c|c|c|}
\hline $\begin{array}{l}\text { Baldwin \& Costley, } \\
2016\end{array}$ & $\begin{array}{l}\text { Mixed-method } \\
\text { Survey (online, mail) }\end{array}$ & $\begin{array}{l}\text { Female individuals on the } \\
\text { autism spectrum: } n=82\end{array}$ & $\begin{array}{l}\text { 18-64 } \\
\text { Mean: } 32.7\end{array}$ & Australia & $\begin{array}{l}\text { To assess the health, education, } \\
\text { work, social, and community } \\
\text { activities of autistic adult females }\end{array}$ \\
\hline
\end{tabular}

Acceptability: Extra personal

stigma, delayed diagnosis

Appropriateness: Cognitive

ability

\author{
Appropriateness: \\ Communication barriers, \\ provider knowledge, past \\ negative experiences with care \\ providers
}

Acceptability: Extra personal stigma, intrapersonal stigma

Availability: Lack of or cost of transportation

Affordability: Other financial priorities

Approachability: Health care

system complexity 


\begin{tabular}{|c|c|c|c|c|c|c|}
\hline $\begin{array}{l}\text { Nicolaidis et al., } \\
2013\end{array}$ & $\begin{array}{l}\text { Mixed-methods } \\
\text { Cross-sectional online } \\
\text { survey and Community } \\
\text { Based Participatory } \\
\text { Research (online data } \\
\text { collection) }\end{array}$ & $\begin{array}{l}\text { Adults older than } \\
\text { 18-year-old } \\
\text { Adults on the autism } \\
\text { spectrum: } n=209 \\
\text { Adults not on the autism } \\
\text { spectrum: } n=228\end{array}$ & $\begin{array}{l}\text { Adults on the } \\
\text { autism spectrum: } \\
\text { Mean; } 37.3 \mathrm{SD} \text { : } \\
12.7\end{array}$ & USA & $\begin{array}{l}\text { To compare the health care } \\
\text { experiences of autistic and } \\
\text { non-individuals on the autism } \\
\text { spectrum }\end{array}$ & $\begin{array}{l}\text { Appropriateness: } \\
\text { Communication barriers, } \\
\text { inadequate services for needs, } \\
\text { lack of supportive care } \\
\text { Acceptability: Extra personal } \\
\text { stigma } \\
\text { Approachability: Health care } \\
\text { system complexity }\end{array}$ \\
\hline Tint \& Weiss, 2018 & $\begin{array}{l}\text { Qualitative } \\
\text { Focus Groups }\end{array}$ & $\begin{array}{l}\text { Female individuals on the } \\
\text { autism spectrum: } n=20\end{array}$ & $\begin{array}{l}\text { 19-69 } \\
\text { Mean: } 35.45 \\
\text { SD: } 12.26\end{array}$ & Canada & $\begin{array}{l}\text { To explore questions with female } \\
\text { autistic adults: 1) perception of } \\
\text { support/care 2) identify unmet } \\
\text { needs 3) identify barriers to access }\end{array}$ & $\begin{array}{l}\text { Appropriateness: } \\
\text { Communication barriers, } \\
\text { provider knowledge, inadequate } \\
\text { services for needs, lack of } \\
\text { supportive care } \\
\text { Acceptability: Extra personal } \\
\text { stigma } \\
\text { Availability: Lack of or cost of } \\
\text { transportation }\end{array}$ \\
\hline $\begin{array}{l}\text { Saqr, Braun, Porter, } \\
\text { Barnette, \& Hanks, } \\
2018\end{array}$ & $\begin{array}{l}\text { Qualitative } \\
\text { Focus Group and } \\
\text { Retrospective } \\
\text { Cross-Sectional study }\end{array}$ & $\begin{array}{l}\text { Individuals on the autism } \\
\text { spectrum: } \mathrm{n}=10\end{array}$ & $18-30$ & USA & $\begin{array}{l}\text { To explore the clinical experiences } \\
\text { and unmet needs for individuals on } \\
\text { the autism spectrum }\end{array}$ & $\begin{array}{l}\text { Appropriateness: } \\
\text { Communication barriers, sensory } \\
\text { overload }\end{array}$ \\
\hline Lai \& Weiss, 2017 & $\begin{array}{l}\text { Quantitative } \\
\text { Online Survey }\end{array}$ & $\begin{array}{l}\text { Caregivers on behalf of } \\
\text { individuals on the autism } \\
\text { spectrum: } n=755\end{array}$ & $2-61$ & Canada & $\begin{array}{l}\text { To identify priority service needs } \\
\text { across age groups }\end{array}$ & $\begin{array}{l}\text { Affordability: Could not afford } \\
\text { desired services }\end{array}$ \\
\hline
\end{tabular}




\begin{tabular}{|c|c|c|c|c|c|c|}
\hline $\begin{array}{l}\text { Nicolaidis et al., } \\
2015\end{array}$ & $\begin{array}{l}\text { Qualitative } \\
\text { Semi-structured open } \\
\text { ended } \\
\text { Interviews (Telephone, } \\
\text { email, in-person or } \\
\text { instant messenger) }\end{array}$ & $\begin{array}{l}\text { Caregivers and Health care } \\
\text { Providers for individuals } \\
\text { on the autism spectrum } \\
\text { and individuals on the } \\
\text { autism spectrum } \\
\text { Adults on the spectrum: } \\
\mathrm{n}=39 \\
\text { Caregivers: } \mathrm{n}=16\end{array}$ & $\begin{array}{l}\text { Adults on the } \\
\text { spectrum: } 19-64 \\
\text { Mean: } 35 \\
\text { Caregivers: } 28-74 \\
\text { Mean: } 52\end{array}$ & USA & $\begin{array}{l}\text { To further understanding of the } \\
\text { health care experiences for } \\
\text { individuals on the autism spectrum } \\
\text { and put forth recommendations for } \\
\text { improvements }\end{array}$ & $\begin{array}{l}\text { Appropriateness: } \\
\text { Communication barriers, sensory } \\
\text { overload, provider knowledge, } \\
\text { inadequate service for needs, the } \\
\text { complexity of family } \\
\text { involvement } \\
\text { Acceptability: Extra personal } \\
\text { stigma } \\
\text { Approachability: Health care } \\
\text { system complexity }\end{array}$ \\
\hline $\begin{array}{l}\text { Blomqvist, Bejerot, } \\
\text { \& Dahllöf, } 2015\end{array}$ & $\begin{array}{l}\text { Quantitative } \\
\text { Cross-sectional study: } \\
\text { dental examination and } \\
\text { questionnaire }\end{array}$ & $\begin{array}{l}\text { Individuals on the autism } \\
\text { spectrum } \\
\text { Adults on the autism } \\
\text { spectrum: } n=47 \\
\text { Adults not on the autism } \\
\text { spectrum: } n=69\end{array}$ & $\begin{array}{l}\text { Individuals on the } \\
\text { autism spectrum: } \\
25-41 \\
\text { Individuals not on } \\
\text { the autism } \\
\text { spectrum: } 27-41\end{array}$ & Sweden & $\begin{array}{l}\text { To investigate oral health behavior } \\
\text { and dental care for individuals on } \\
\text { the autism spectrum }\end{array}$ & $\begin{array}{l}\text { Appropriateness: } \\
\text { Communication barriers }\end{array}$ \\
\hline $\begin{array}{l}\text { Lum, Garnett, \& } \\
\text { O'Connor, } 2014\end{array}$ & $\begin{array}{l}\text { Qualitative } \\
\text { Pilot study, survey } \\
\text { (online, mail) }\end{array}$ & $\begin{array}{l}\text { Adult females } \\
\text { Adults on the autism } \\
\text { spectrum: } n=32 \\
\text { Adults not on the autism } \\
\text { spectrum } n=16\end{array}$ & $\begin{array}{l}\text { Adults on the } \\
\text { autism spectrum: } \\
18-64 \\
\text { Adults not on the } \\
\text { autism spectrum: } \\
\text { 18-64 }\end{array}$ & Australia & $\begin{array}{l}\text { To investigate the disparity in } \\
\text { health care service challenges } \\
\text { between high functioning autistic } \\
\text { adult females compared to } \\
\text { non-autistic adult women }\end{array}$ & $\begin{array}{l}\text { Appropriateness: } \\
\text { Communication barriers, sensory } \\
\text { overload, lack of supportive care, } \\
\text { anxiety and fear } \\
\text { Acceptability: Extra personal } \\
\text { stigma }\end{array}$ \\
\hline
\end{tabular}




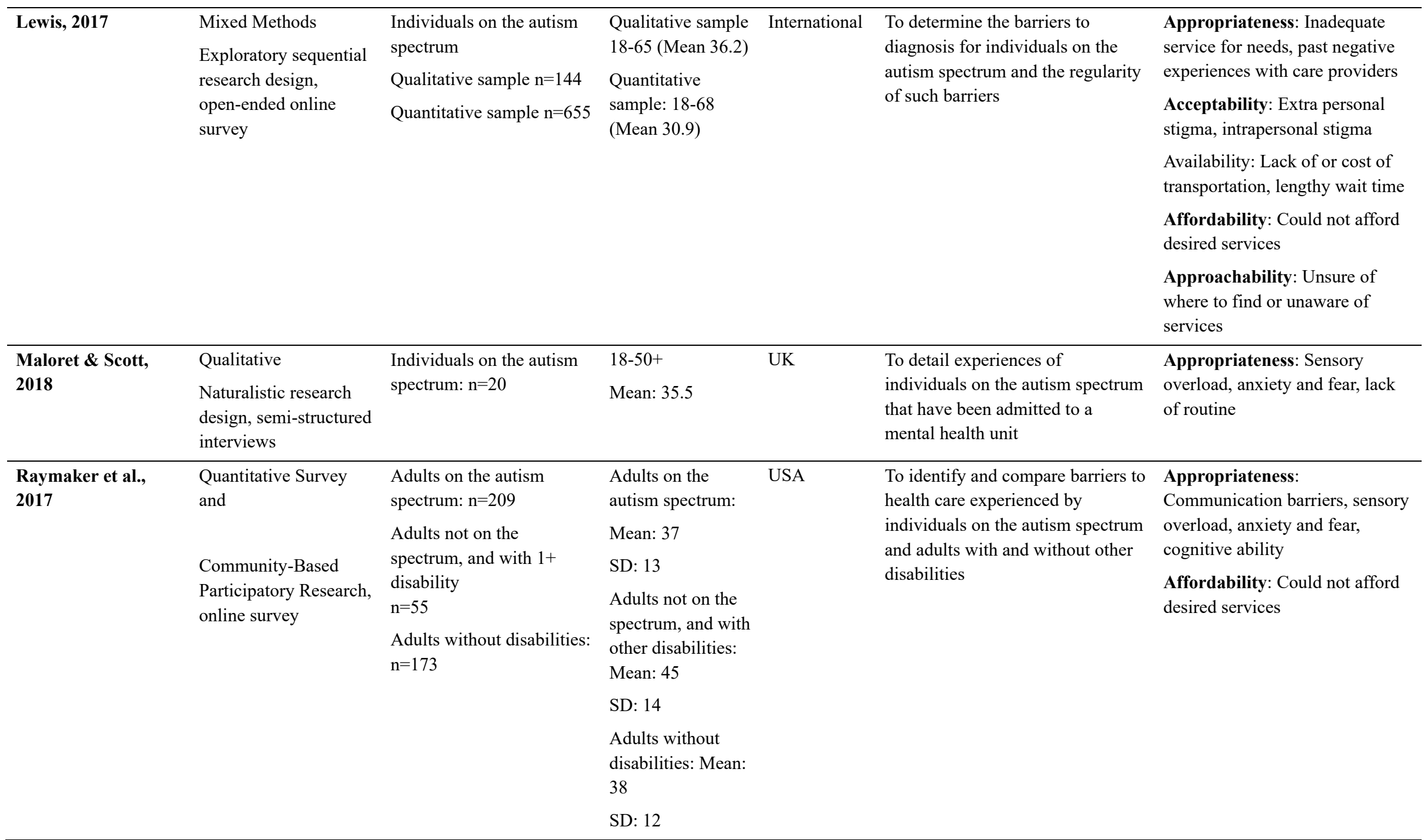




\begin{tabular}{|c|c|c|c|c|c|c|}
\hline $\begin{array}{l}\text { Warfield, Crossman, } \\
\text { Delahaye, Der } \\
\text { Weerd, \& Kuhlthau, } \\
2015\end{array}$ & $\begin{array}{l}\text { Qualitative } \\
\text { Case study, telephone } \\
\text { interview }\end{array}$ & $\begin{array}{l}\text { Health care providers that } \\
\text { serve individuals on the } \\
\text { autism spectrum } \\
\mathrm{n}=10\end{array}$ & Not reported & USA & $\begin{array}{l}\text { To explore the training, challenges, } \\
\text { ideas for improvement, and } \\
\text { interest of health care providers } \\
\text { that serve individuals on the } \\
\text { autism spectrum }\end{array}$ & $\begin{array}{l}\text { Appropriateness: } \\
\text { Communication barriers, sensory } \\
\text { overload, provider knowledge, } \\
\text { inadequate services for needs, the } \\
\text { complexity of family } \\
\text { involvement }\end{array}$ \\
\hline
\end{tabular}

Acceptability: Extra personal

stigma

Affordability: Financial

disincentives for providers

\begin{tabular}{|c|c|c|c|c|c|c|}
\hline Crane et al., 2018 & $\begin{array}{l}\text { Qualitative } \\
\text { Telephone interviews }\end{array}$ & $\begin{array}{l}\text { Adults on the autism } \\
\text { spectrum, parents of adults } \\
\text { on the autism spectrum, } \\
\text { and health care providers } \\
\text { that serve individuals on } \\
\text { the autism spectrum } \\
n=10\end{array}$ & $\begin{array}{l}29-59 \\
\text { Mean: } 42.89 \\
\text { SD: } 11.71\end{array}$ & UK & $\begin{array}{l}\text { To explore the diagnostic process } \\
\text { for individuals on the autism } \\
\text { spectrum and seek to determine } \\
\text { recommendations for improved } \\
\text { services }\end{array}$ & $\begin{array}{l}\text { Appropriateness: Sensory } \\
\text { overload, provider knowledge, } \\
\text { lack of supportive care, past } \\
\text { negative experiences with care } \\
\text { providers } \\
\text { Acceptability: Extra personal } \\
\text { stigma } \\
\text { Affordability: Financial } \\
\text { disincentives for providers } \\
\text { Approachability: Unsure of } \\
\text { where to find or unaware of } \\
\text { services }\end{array}$ \\
\hline $\begin{array}{l}\text { Camm-Crosbie, } \\
\text { Bradley, Shaw, } \\
\text { Baron-Cohen, \& } \\
\text { Cassidy, } 2019\end{array}$ & $\begin{array}{l}\text { Qualitative } \\
\text { Online survey (closed } \\
\text { and open-ended } \\
\text { questions) }\end{array}$ & $\begin{array}{l}\text { Individuals on the autism } \\
\text { spectrum: } n=200\end{array}$ & $\begin{array}{l}18-67 \\
\text { Mean: } 38.9 \\
\text { SD: } 11.5\end{array}$ & UK & $\begin{array}{l}\text { To explore the experiences of } \\
\text { treatment and support for mental } \\
\text { health problems, self-injury and } \\
\text { suicidality among individuals on } \\
\text { the autism spectrum }\end{array}$ & $\begin{array}{l}\text { Appropriateness: Provider } \\
\text { knowledge, inadequate service } \\
\text { for needs, lack of supportive care } \\
\text { Acceptability: Extra personal } \\
\text { stigma } \\
\text { Availability: Lack of or cost of } \\
\text { transportation, lengthy wait time } \\
\text { Affordability: Could not afford } \\
\text { desired services }\end{array}$ \\
\hline
\end{tabular}




\begin{tabular}{|c|c|c|c|c|c|c|}
\hline $\begin{array}{l}\text { Lipinski, Blanke, } \\
\text { Suenkel, \& Dziobek, } \\
2019\end{array}$ & $\begin{array}{l}\text { Mixed Methods } \\
\text { Participatory Research } \\
\text { Approach, Online } \\
\text { survey }\end{array}$ & $\begin{array}{l}\text { Individuals on the autism } \\
\text { spectrum and adults with } \\
\text { Major Depressive Disorder } \\
\text { (MDD) } \\
\mathrm{n}=245 \text { individuals on the } \\
\text { autism spectrum } \\
\mathrm{n}=245 \text { adults with MDD }\end{array}$ & $\begin{array}{l}18+ \\
\text { ASD group mean: } \\
37 \\
\text { MDD group mean: } \\
42\end{array}$ & Germany & $\begin{array}{l}\text { To explore the use of } \\
\text { psychotherapy among individuals } \\
\text { on the autism spectrum }\end{array}$ & $\begin{array}{l}\text { Appropriateness: } \\
\text { Communication barriers, sensory } \\
\text { overload, provider knowledge } \\
\text { Approachability: Health care } \\
\text { system complexity }\end{array}$ \\
\hline $\begin{array}{l}\text { Vohra, Madhavan, } \\
\text { \& Sambamoorthi, } \\
2016\end{array}$ & $\begin{array}{l}\text { Quantitative } \\
\text { Cross-sectional } \\
\text { matched case-control } \\
\text { design }\end{array}$ & $\begin{array}{l}\text { Individuals on the autism } \\
\text { spectrum and individuals } \\
\text { not on the autism spectrum } \\
n=102,108 \text { ED visits }\end{array}$ & $22-64$ & USA & $\begin{array}{l}\text { To examine trends and types of } \\
\text { emergency department visits by } \\
\text { autistic and non-individuals on the } \\
\text { autism spectrum }\end{array}$ & $\begin{array}{l}\text { Appropriateness: Inadequate } \\
\text { service for needs }\end{array}$ \\
\hline Henry, 2013 & $\begin{array}{l}\text { Qualitative } \\
\text { Interviews }\end{array}$ & $\begin{array}{l}\text { Parent/ caretaker on behalf } \\
\text { of an adult on the } \\
\text { spectrum: } n=8\end{array}$ & $21-54$ & USA & $\begin{array}{l}\text { To identify perceived barriers to } \\
\text { health care access for individuals } \\
\text { on the autism spectrum and to } \\
\text { determine if social networks } \\
\text { influence access to these resources } \\
\text { successfully }\end{array}$ & $\begin{array}{l}\text { Appropriateness: Provider } \\
\text { knowledge, inadequate service } \\
\text { for needs } \\
\text { Affordability: Lack of insurance } \\
\text { coverage }\end{array}$ \\
\hline $\begin{array}{l}\text { Au-Yeung et al., } \\
2019\end{array}$ & $\begin{array}{l}\text { Mixed-Method } \\
\text { online surveys }\end{array}$ & $\begin{array}{l}\text { Adults on the autism } \\
\text { spectrum, Adults that may } \\
\text { be on the autism spectrum, } \\
\text { Adults not on the autism } \\
\text { spectrum: } n=420\end{array}$ & $\begin{array}{l}\text { Adults on the } \\
\text { spectrum:18-67 } \\
\text { Mean: } 38.6 \\
\text { SD } 11.4 \\
\text { Possible ASD: } \\
\text { 20-57 } \\
\text { Mean: } 40.1 \\
\text { SD: } 8.9 \\
\text { Non-ASD: } 20-60 \\
\text { Mean: } 42.1 \\
\text { SD: } 10.6\end{array}$ & $\begin{array}{l}\text { United } \\
\text { Kingdom }\end{array}$ & $\begin{array}{l}\text { Understand the differences in } \\
\text { mental health diagnoses for } \\
\text { autistic and non-individuals on the } \\
\text { autism spectrum }\end{array}$ & $\begin{array}{l}\text { Appropriateness: } \\
\text { Communication barriers, } \\
\text { provider knowledge, inadequate } \\
\text { services for needs }\end{array}$ \\
\hline
\end{tabular}




\begin{tabular}{|c|c|c|c|c|c|c|}
\hline Rodgers et al., 2019 & $\begin{array}{l}\text { Qualitative } \\
\text { Focus Groups }\end{array}$ & $\begin{array}{l}\text { Individuals on the autism } \\
\text { spectrum: } n=23\end{array}$ & $\begin{array}{l}18-64 \\
\text { Mean: } 35 \\
\text { SD: } 13\end{array}$ & $\begin{array}{l}\text { United } \\
\text { Kingdom }\end{array}$ & $\begin{array}{l}\text { To explore the nature of the } \\
\text { worries individuals on the autism } \\
\text { spectrum have about their futures }\end{array}$ & $\begin{array}{l}\text { Appropriateness: } \\
\text { Communication barriers, } \\
\text { providers knowledge } \\
\text { Acceptability: Extra personal } \\
\text { stigma } \\
\text { Approachability: Health care } \\
\text { system complexity, unsure where } \\
\text { to find or unaware of services }\end{array}$ \\
\hline $\begin{array}{l}\text { Stein Duker et al., } \\
2019\end{array}$ & $\begin{array}{l}\text { Mixed-Method } \\
\text { Surveys }\end{array}$ & $\begin{array}{l}\text { Adults on the autism } \\
\text { spectrum, caregivers and } \\
\text { primary care providers } \\
\mathrm{n}=78\end{array}$ & $\begin{array}{l}18+ \\
\text { Adults on the } \\
\text { autism spectrum } \\
\text { Mean: } 31.5 \\
\text { SD: } 12 \\
\text { Caregivers } \\
\text { Mean: } 24.3 \\
\text { SD: } 6.6\end{array}$ & USA & $\begin{array}{l}\text { To explore barriers and strategies } \\
\text { to improve primary care } \\
\text { encounters amongst adults on the } \\
\text { autism spectrum. }\end{array}$ & $\begin{array}{l}\text { Appropriateness: } \\
\text { Communication barriers, } \\
\text { providers knowledge, sensory } \\
\text { overload, cognitive ability } \\
\text { Acceptability: Extra personal } \\
\text { stigma } \\
\text { Approachability: Unsure where } \\
\text { to find or unaware of services, } \\
\text { health care system complexity } \\
\text { Availability: Lack of } \\
\text { transportation options } \\
\text { Affordability: Could not afford } \\
\text { desired services }\end{array}$ \\
\hline Mason et al., 2019 & Systematic Review & Not reported & Not reported & $\begin{array}{l}\text { United } \\
\text { Kingdom }\end{array}$ & $\begin{array}{l}\text { To explore the barriers and } \\
\text { facilitators of healthcare access for } \\
\text { individuals on the autism } \\
\text { spectrum. }\end{array}$ & $\begin{array}{l}\text { Appropriateness: } \\
\text { Communication barriers, sensory } \\
\text { overload }\end{array}$ \\
\hline
\end{tabular}


Table 3. List of citations categorized into each dimension of access

\section{Citations}

\begin{tabular}{|c|c|c|}
\hline \multirow{10}{*}{ 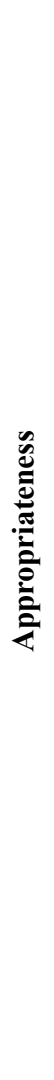 } & Communication barriers & $\begin{array}{l}\text { Au-Yeung et al., 2019; Blomqvist et al., 2015; Lewis, 2017; Lipinski et al., 2019; Lum et al., 2014; Mason et al., 2019; } \\
\text { Nicolaidis et al., 2013, 2015; Raymaker et al., 2017; Saqr et al., 2018; Stein Duker et al., 2019; Tint \& Weiss, 2018; Vogan } \\
\text { et al., 2017; Warfield et al., } 2015\end{array}$ \\
\hline & Sensory overload & $\begin{array}{l}\text { Crane et al., 2018; Lipinski et al., 2019; Lum et al., 2014; Maloret \& Scott, 2018; Mason et al., 2019; Nicolaidis et al., } \\
\text { 2015; Raymaker et al., 2017; Saqr et al., 2018; Stein Duker et al., 2019; Warfield et al., } 2015\end{array}$ \\
\hline & Provider knowledge & $\begin{array}{l}\text { Au-Yeung et al., 2019; Camm-Crosbie et al., 2019; Crane et al., 2018; Henry, 2013; Lipinski et al., 2019; Mason et al., } \\
\text { 2019; Nicolaidis et al., 2015; Tint \& Weiss, 2018; Vogan et al., 2017; Warfield et al., } 2015\end{array}$ \\
\hline & Inadequate service for needs & $\begin{array}{l}\text { Au-Yeung et al., 2019; Camm-Crosbie et al., 2019; Henry, 2013; Lewis, 2017; Nicolaidis et al., 2013, 2015; Rodgers et } \\
\text { al., 2019; Stein Duker et al., 2019; Tint \& Weiss, 2018; Vohra et al., 2016; Warfield et al., } 2015\end{array}$ \\
\hline & Lack of supportive care & Camm-Crosbie et al., 2019; Crane et al., 2018; Lum et al., 2014; Nicolaidis et al., 2013; Tint \& Weiss, 2018 \\
\hline & Anxiety and fear & Lewis, 2017; Lum et al., 2014; Maloret \& Scott, 2018; Raymaker et al., 2017 \\
\hline & Past negative experiences with $\mathrm{HCP}$ & Au-Yeung et al., 2019; Crane et al., 2018; Lewis, 2017; Mason et al., 2019; Vogan et al., 2017 \\
\hline & Cognitive ability & Bruder et al., 2012; Mason et al., 2019; Raymaker et al., 2017; Stein Duker et al., 2019 \\
\hline & The complexity of family involvement & Nicolaidis et al., 2015; Warfield et al., 2015 \\
\hline & Lack of routine & Maloret \& Scott, 2018 \\
\hline
\end{tabular}




\begin{tabular}{|c|c|c|}
\hline \multirow{2}{*}{ 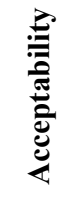 } & Extra personal stigma & $\begin{array}{l}\text { Baldwin \& Costley, 2016; Camm-Crosbie et al., 2019; Crane et al., 2018; Lewis, 2017; Lum et al., 2014; Nicolaidis et al., } \\
\text { 2013, 2015; Rodgers et al., 2019; Stein Duker et al., 2019; Tint \& Weiss, 2018; Vogan et al., 2017; Warfield et al., } 2015\end{array}$ \\
\hline & Intrapersonal stigma & Lewis, 2017; Vogan et al., 2017 \\
\hline \multirow{3}{*}{ 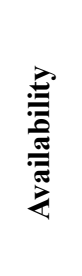 } & Lack of or cost of transportation & $\begin{array}{l}\text { Camm-Crosbie et al., 2019; Dudley et al., 2019; Lewis, 2017; Stein Duker et al., 2019; Tint \& Weiss, 2018; Vogan et al., } \\
2017\end{array}$ \\
\hline & Lengthy wait time & Camm-Crosbie et al., 2019; Lewis, 2017 \\
\hline & Delayed diagnosis & Baldwin \& Costley, 2016 \\
\hline \multirow{5}{*}{ 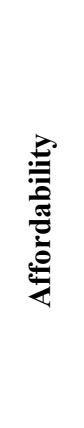 } & Could not afford desired services & Camm-Crosbie et al., 2019; Lai \& Weiss, 2017; Lewis, 2017; Raymaker et al., 2017; Stein Duker et al., 2019 \\
\hline & Financial disincentive for providers & Crane et al., 2018; Warfield et al., 2015 \\
\hline & Lack of insurance coverage & Henry, 2013 \\
\hline & Other financial priorities & Vogan et al., 2017 \\
\hline & Living situations lead to less funding & Dudley et al., 2019 \\
\hline \multirow{2}{*}{ 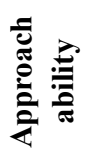 } & Health care system complexity & Lipinski et al., 2019; Nicolaidis et al., 2013, 2015; Rodgers et al., 2019; Stein Duker et al., 2019; Vogan et al., 2017 \\
\hline & Unsure of where to find or unaware of services & Crane et al., 2018; Dudley et al., 2019; Lewis, 2017; Rodgers et al., 2019; Stein Duker et al., 2019 \\
\hline
\end{tabular}




\section{Results}

\subsection{Search Results}

After the database search yielded 2816 unique articles, a title and abstract screen narrowed the search to 160 articles for full-text review. The full texts of the 160 articles were reviewed, and 24 articles were included in this scoping review to answer the question "How do individuals on the autism spectrum access and experience health care services?" Articles were excluded when the content did not discuss individuals on the autism spectrum accessing care $(\mathrm{n}=68)$, the study population was children or transitioning youth $(\mathrm{n}=55)$, the sample was not specific to individuals on the autism spectrum $(n=12)$, or the article was not in English $(n=1)$. A PRISMA flow chart of this process can be viewed in Figure 1.

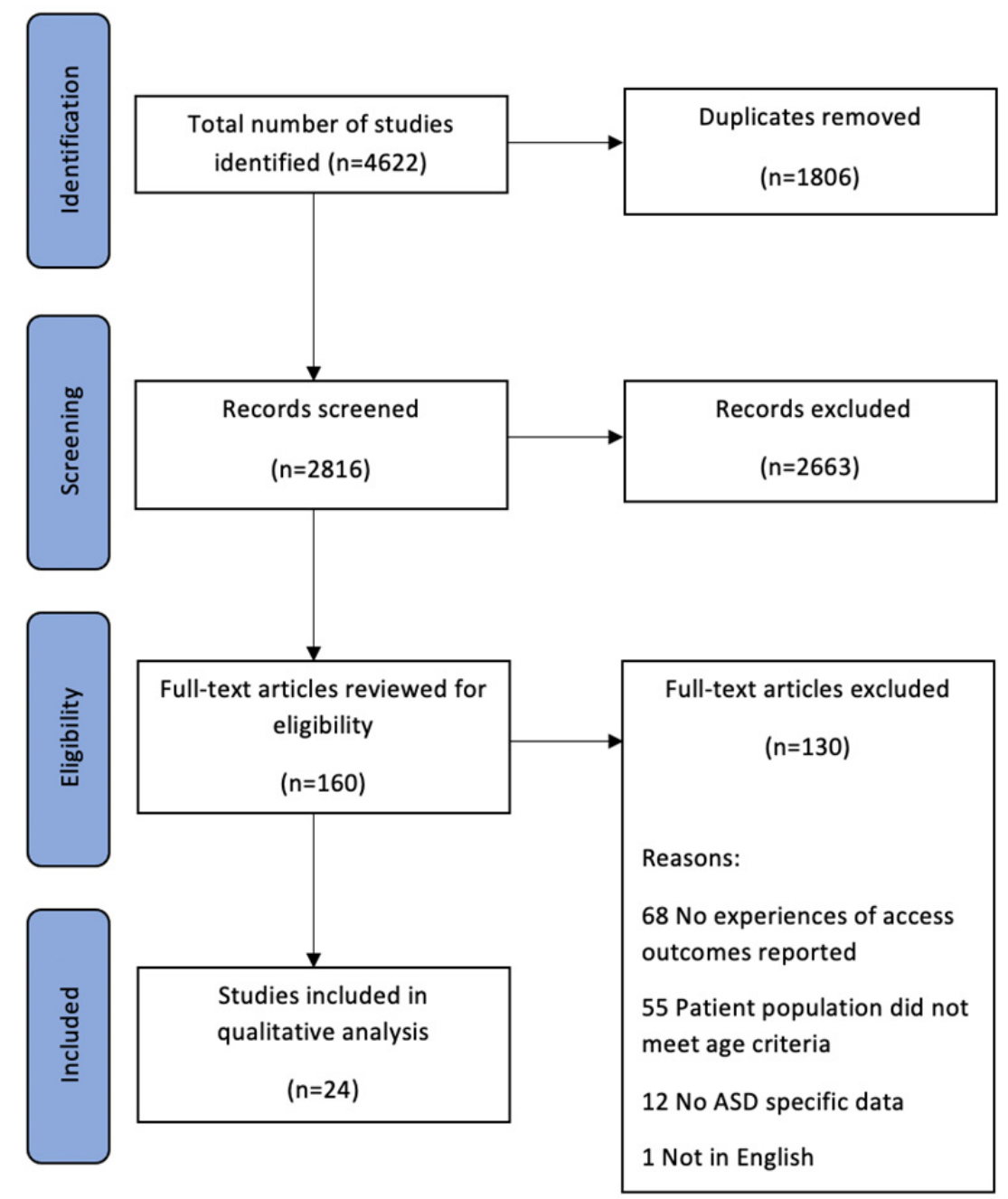

Figure 1. PRISMA chart

\subsection{Study Design, Demographics, and Country of Origin}

Of the 24 included articles, ten were qualitative, six were quantitative, seven were mixed methods, and one was a review article. Ten of the 24 studies had a majority of female participants, 2 of which included a sample made up of $100 \%$ females. Ten more of the studies had most male participants, and in the four remaining studies, gender was not reported. The articles were based on five countries' data: ten studies from the United States of America, three from Canada, six from the United Kingdom, two from Australia, one from Sweden, one from Germany and one included a multinational sample. 


\subsection{Appropriateness}

The dimension of access that was most often cited was the dimension of appropriateness. Within this dimension, one consistent theme reported in 14 of the 24 articles was communication challenges between the provider and adults on the autism spectrum posing as a barrier to care (Au-Yeung et al., 2019; Blomqvist et al., 2015; Lewis, 2017; Lipinski et al., 2019; Lum et al., 2014; Mason et al., 2019; Nicolaidis et al., 2013, 2015; Raymaker et al., 2017; Saqr et al., 2018; Stein Duker et al., 2019; Tint \& Weiss, 2018; Vogan et al., 2017; Warfield et al., 2015). When looking more in-depth at the root of these communication challenges, it was clear that challenges arise from both the provider and the client's perspectives. Communication difficulties that originated from the provider's side encompassed interactions in which a provider spoke in inaccessible ways such as being overly reliant on jargon, speaking too quickly or other such patterns that made it hard for the client on the autism spectrum to follow (Blomqvist et al., 2015; Lewis, 2017; Lipinski et al., 2019; Lum et al., 2014; Mason et al., 2019; Nicolaidis et al., 2013, 2015; Raymaker et al., 2017; Saqr et al., 2018; Stein Duker et al., 2019; Tint \& Weiss, 2018; Vogan et al., 2017; Warfield et al., 2015). One study compared the experience of individuals on the autism spectrum and neurotypical adults through an online survey (Nicolaidis et al., 2013). The individuals on the autism spectrum scored significantly lower in questions related to communication such as: "health professionals gave me the chance to ask all the health-related questions I had", "health professionals understood what I was trying to communicate", and "health professionals communicated in a way I could understand" (Nicolaidis et al., 2013). Another study by the same team reported the experience of providers being unwilling to allow patients on the autism spectrum to communicate in writing when that was their preference (Nicolaidis et al., 2015). Communication challenges were reported by individuals on the autism spectrum in regards to their abilities as well such as feeling unable to express their feelings and explain their symptoms resulting in care that did not meet their needs (Au-Yeung et al., 2019; Blomqvist et al., 2015; Lewis, 2017; Lipinski et al., 2019; Lum et al., 2014; Mason et al., 2019; Nicolaidis et al., 2013, 2015; Raymaker et al., 2017; Saqr et al., 2018; Tint \& Weiss, 2018; Vogan et al., 2017; Warfield et al., 2015). A specific example of this is a study focused on women with "high functioning" ASD and their experience with maternity care. It found that women on the autism spectrum experience a decreased ability to communicate pain and needs during childbirth (Lum et al., 2014). Still, another individual stated that they had significant difficulties with communicating their needs to health providers and, "after obtaining medical notes, it [was] clear that my account of my experiences were... misunderstood and I was not given opportunities to clarify" (Au-Yeung et al., 2019).

Another frequently reported theme among the included articles related to the appropriateness of care was the sensory overload in health care settings that individuals on the autism spectrum experience (Crane et al., 2018; Lipinski et al., 2019; Lum et al., 2014; Maloret \& Scott, 2018; Mason et al., 2019; Nicolaidis et al., 2015; Raymaker et al., 2017; Saqr et al., 2018; Stein Duker et al., 2019; Warfield et al., 2015). Adults who took part in a focus group study concluded that the sensory overload in the waiting room and physical examinations are the most stressful parts of a health care visit (Saqr et al., 2018). This was backed by three qualitative studies that reported the presence of other people and stimulation in waiting rooms created anxiety for individuals on the autism spectrum before their appointments began (Lum et al., 2014; Nicolaidis et al., 2015; Warfield et al., 2015). In rare instances, the heightened anxiety led to acts of physical violence towards other patients in the waiting room (Warfield et al., 2015).

Multiple studies reported from the patient's perspective showed that inadequately trained staff and health care professionals lacked knowledge about the needs of individuals on the autism spectrum and how to provide care for the spectrum of adults in this population (Au-Yeung et al., 2019; Camm-Crosbie et al., 2019; Crane et al., 2018; Henry, 2013; Lipinski et al., 2019; Mason et al., 2019; Nicolaidis et al., 2015; Tint \& Weiss, 2018; Vogan et al., 2017; Warfield et al., 2015). Individuals on the autism spectrum reported physicians who lack knowledge of the autism spectrum presented the diagnosis to patients in a negative light, focusing on associated deficits rather than adopting a strength-based approach (Crane et al., 2018). Individuals on the autism spectrum have expressed that physicians regularly underestimate their abilities and limit their autonomy in the care process because of their poor understanding of the condition (Nicolaidis et al., 2015). Health care providers also attest to this knowledge gap. One qualitative study specifically looked at the physician perspective of individuals on the autism spectrum accessing health care by collecting data through in-depth case studies with nine doctors and one nurse who provided primary medical care to individuals on the autism spectrum (Warfield et al., 2015). The results of this study reported that health care providers felt unprepared to provide appropriate services for individuals on the autism spectrum (Warfield et al., 2015). Providers pointed to insufficient training and education during their school and the workforce (Warfield et al., 2015). This lack of knowledge and skills leaves providers feeling unable to provide adequate care, which often causes them to shy away from taking on individuals on the autism spectrum as 
clients (Warfield et al., 2015).

Individuals on the autism spectrum and their caregivers also reported inadequacy of the services offered, with care not fitting their needs or a lack of appropriate treatment, support, and resources (Au-Yeung et al., 2019; Camm-Crosbie et al., 2019; Henry, 2013; Lewis, 2017; Nicolaidis et al., 2013, 2015; Rodgers et al., 2019; Stein Duker et al., 2019; Tint \& Weiss, 2018; Vohra et al., 2016; Warfield et al., 2015). Care for individuals on the autism spectrum is often poorly tailored and is delivered in a "one size fits all" manner that results in many individuals on the autism spectrum receiving inadequate care (Tint \& Weiss, 2018). Researchers emphasize that problems adults on the autism spectrum might have can present in many ways, and therefore, generic care can be unhelpful. In addition to inadequate care, many studies reported unsupportive care as an additional barrier (Camm-Crosbie et al., 2019; Crane et al., 2018; Lum et al., 2014; Nicolaidis et al., 2013; Tint \& Weiss, 2018). There is evidence that providers do not communicate enough information to help individuals on the autism spectrum understand options and participate in the decision-making process (Lum et al., 2014; Nicolaidis et al., 2013). In a study of women on the autism spectrum, participants reported a feeling of decreased support and overall dissatisfaction with the health care system compared to women not on the autism spectrum (Lum et al., 2014). Similarly, in Canada, women on the autism spectrum also reported serious dissatisfaction with their interactions with the health care system (Tint \& Weiss, 2018). These results' convergence highlights the international shortcomings of health systems' ability to appropriately serve adults on the autistic spectrum.

Other barriers related to the appropriateness of care included respondent's anxiety levels and fear (Lewis, 2017; Lum et al., 2014; Maloret \& Scott, 2018; Raymaker et al., 2017), which often were related to past negative experiences with the health care system (Au-Yeung et al., 2019; Crane et al., 2018; Lewis, 2017; Mason et al., 2019; Vogan et al., 2017). A mixed-methods study including 799 individuals on the autism spectrum from 18 countries looked explicitly at the diagnostic process and found participants reported anxiety around making appointments (85\%), attending appointments (82\%), or experienced anxiety during appointments (80\%) (Lewis, 2017). One participant elaborated to explain that due to past negative experiences he was nervous about health care interactions because he feared that he would not be believed and ultimately would receive unhelpful care (Lewis, 2017). Individuals on the autism spectrum also expressed frustration because the medical system is structured in a way that can exceed their cognitive abilities including the comprehension and memory required to understand medical recommendations (Bruder et al., 2012; Mason et al., 2019; Raymaker et al., 2017; Stein Duker et al., 2019). In one study, $32 \%$ of participants reported not being given enough time to process and understand information during medical appointments (Raymaker et al., 2017). This finding suggests that many adults on the autism spectrum could more fully process and participate in their medical care if they were allowed more time to ask questions and consume information. In a study that aimed to understand the physician's perspective of this issue, $57 \%$ of the 346 physicians who completed an online questionnaire reported their patients on the autism spectrum could not understand medical care and therefore required a caregiver to be present (Warfield et al., 2015). Another issue of appropriateness relates to caregiver involvement in health care service provision. An in-depth qualitative study of 10 health care professionals also discussed challenges of providing care when there are two adults in the room and uncertainty in navigating family involvement (Warfield et al., 2015). When caregivers are brought to appointments, the patient's autonomy is diminished. The provider will usually rely on the caregiver rather than taking the time to communicate appropriately with the patient (Nicolaidis et al., 2015). Finally, adults on the autism spectrum living in an inpatient mental health unit experience those above and further barriers of poor unit structure and inconsistent routine patterns that limit their ability to interact with health care providers and receive adequate services (Maloret \& Scott, 2018).

\subsection{Acceptability}

To understand how individuals on the autism spectrum may access health care, we need to understand if they feel comfortable accessing and utilizing the available services. Across the 24 included studies, stigma was discussed in 12, including stigma from health care professionals (Baldwin \& Costley, 2016; Camm-Crosbie et al., 2019; Lewis, 2017; Lum et al., 2014; Nicolaidis et al., 2013, 2015; Stein Duker et al., 2019; Vogan et al., 2017; Warfield et al., 2015), cultural stigma (Lewis, 2017; Vogan et al., 2017), stigma from family (Crane et al., 2018; Lewis, 2017), and personal stigma (Lewis, 2017; Vogan et al., 2017). All types of the stigma created barriers to accessing services for this population.

The presence of self-stigma was explored in a large-scale mixed-method study of 799 adults on the autism spectrum, where $38 \%$ reported to have self-stigma, often portrayed by the belief that they do not deserve or need to access the services that may be available (Lewis, 2017). To compound this self-stigma, Lewis (2017) also found that $68 \%$ of respondents reported stigma from family, friends, or the community as a barrier to seeking a diagnosis. 
Family members often refused to accept the adult's diagnosis for those with a diagnosis, which created complications when seeking and accessing services to meet health needs (Crane et al., 2018). Several articles included in this review also reported individuals on the autism spectrum frequently experiencing stigma from HCPs. Consequences of this stigma led to individuals on the autism spectrum fearing disclosing their diagnosis to new HCPs. Their past experiences led them to fear labelling's harmful effects and the difference in the care they might receive (Lewis, 2017; Lum et al., 2014; Nicolaidis et al., 2015). In one study, $81 \%$ of respondents identified barriers arising from a general cultural belief that autism is strictly a childhood condition (Lewis, 2017). Misunderstanding is often core to the experience of stigma.

\subsection{Availability}

The availability of health services is what people may initially think of when considering access, including aspects of the physical space and location and how it can be accessed promptly (Levesque et al., 2013). Eight of the 24 studies discussed availability to care access. Two quantitative questionnaires of community-dwelling individuals on the autism spectrum found that a quarter of individuals on the autism spectrum required services that were not accessible due to their physical location being too far away (Dudley et al., 2019; Vogan et al., 2017). Transportation also acted as a barrier, studies conducted in multiple countries have shown that both a lack of transportation and the potential expense of paid transportation pose challenges to access (Camm-Crosbie et al., 2019; Dudley et al., 2019; Lewis, 2017; Stein Duker et al., 2019; Tint \& Weiss, 2018; Vogan et al., 2017). The studies reporting these data were quantitative and did not elaborate on what is considered too far or too expensive for travel. Elements of timely availability also were revealed, with lengthy wait times reported as a barrier in Canada and the UK (Camm-Crosbie et al., 2019; Lewis, 2017).

Further research specific to mental health services identified $73 \%$ of the 799 adults on the autism spectrum included in the study report long wait times to access mental health professionals (Lewis, 2017). Similarly, a study of access to mental health services found lengthy waiting lists reported as a barrier to services (Camm-Crosbie et al., 2019). Other availability components included adults experiencing delayed diagnosis, which prevented access to autism-specific services (Baldwin et al., 2014).

\subsection{Affordability}

Ten of the included articles discussed affordability barriers to access. Among these studies, the burden of the economic capacity to pay for care was the primary discussion. Participants who could not afford the desired services were primarily based out of the United States of America (Dudley et al., 2019; Henry, 2013; Raymaker et al., 2017; Stein Duker et al., 2019; Warfield et al., 2015), Canada (Lai \& Weiss, 2017; Vogan et al., 2017), the United Kingdom (Camm-Crosbie et al., 2019; Crane et al., 2018), and one multinational study that focused on the former three countries (Lewis, 2017). Studies from other countries did not address affordability.

Affordability must be understood from both the provider and patient perspectives. From the physicians' perspective, financial disincentives to service provision result in poor care availability for adults on the autism spectrum. International health care providers agree that there are disincentives to take on individuals on the autism spectrum as part of the caseload (Crane et al., 2018; Warfield et al., 2015). Physicians in the US and UK acknowledged a variety of financial burdens that encumbered their care for adults on the autism spectrum. Some of these burdens included the need for additional staff to support the clients, longer appointment times to accommodate diverse needs, complex reimbursement systems, and caseload overflow due to little provider availability (Crane et al., 2018; Warfield et al., 2015).

From the patient perspective, health care will not be accessible if it imposes a financial burden and prevents individuals on the autism spectrum from seeking services. A Canadian study found that $37 \%$ of individuals on the autism spectrum reported they had other financial priorities aside from medical expenses. A small American study of eight participants found adults on the autism spectrum lacked insurance plan benefits that would allow them to access appropriate care (Henry, 2013; Vogan et al., 2017). One American quantitative study that focused on how one's living situation would impact service usage found adults on the autism spectrum who live with family receive significantly more government aid than individuals on the autism spectrum living alone (Dudley et al., 2019). However, all adults on the autism spectrum living outside of supported living facilities such as long-term care were less likely to receive government-funded services (Dudley et al., 2019). Another American-based researcher found that most insurance plans do not cover therapy that help clients maintain function or assist in independent living, such as psychotherapy or occupational therapy, hindering the individual's ability to access health care (Henry, 2013). These findings speak to the broader idea that individuals on the autism spectrum are not provided with the financial support they need to prioritize health care and seek out services they need. Most notably, the American health insurance system is not built to promote these adults' financial freedom as they seek 
out health services.

\subsection{Approachability}

Nine of the articles reported approachability barriers to care access for adults on the autism spectrum. The themes found in the approachability dimension of access were related to the health beliefs and health literacy levels of individuals on the autism spectrum. The barriers noted in this dimension were related to system-level complexity and poor awareness of the services available to individuals. To avoid these barriers, services must be transparent, providing all applicable information to potential clients in an approachable manner (Levesque et al., 2013). One of the cited barriers to the approachability of services for individuals on the autism spectrum was the complexity of the health care system (Lipinski et al., 2019; Nicolaidis et al., 2013, 2015; Rodgers et al., 2019; Stein Duker et al., 2019; Vogan et al., 2017). In a longitudinal study, 52.6\% of respondents reported feeling overwhelmed by the process of seeking care (Vogan et al., 2017). Some individuals on the autism spectrum reported being unsure where to find the service they require (Crane et al., 2018; Dudley et al., 2019; Lewis, 2017; Rodgers et al., 2019; Stein Duker et al., 2019). Many noted feeling directionless when seeking care; one man detailed an experience when he thought he had found a clinical group for individuals on the autism spectrum but instead found himself in a group for parents of children on the autism spectrum (Crane et al., 2018). ASD services are often broad and aim to address this population's many needs, which can be overwhelming and, therefore, a barrier in itself (Crane et al., 2018). Even after accessing initial services, steps within the health care system such as filling prescriptions are also more difficult for adults on the autism spectrum than a typical adult (Nicolaidis et al., 2013).

Further literature shows that newly diagnosed adults on the autism spectrum also believe there are no services available. Of the newly diagnosed adults from Lewis' study, $61 \%$ saw no benefit for their formal diagnosis due to a lack of available services (Lewis, 2017). Adults reported feeling lost following their formal ASD diagnosis and connected with services only once they had reached some type of crisis in their life (Crane et al., 2018). Additionally, adults on the autism spectrum report difficulties identifying available care and navigating the complex process of planning and booking appointments (Lipinski et al., 2019).

\section{Discussion}

In this scoping review, the most prominent barriers for accessing healthcare services are the broad experience of quality care provision and the presence of stigma. The service appropriateness is also challenging for this population. Service appropriateness encompasses communication barriers, sensory appropriateness of the care environment, and provider knowledge. Of the papers included in this review, 18 of the 24 discussed at least one barrier to the dimension of appropriateness, which highlighted the experienced-based challenges to access that individuals on the autism spectrum face. These barriers reflect a need for a greater understanding of ASD in adulthood by the health care community. The majority of physicians reported a lack of training in caring for adults on the autism spectrum. Still, those physicians who did serve individuals on the autism spectrum indicated a significantly greater need for training (Bruder et al., 2012). At the same time, those without this experience are less likely to acknowledge this gap, contributing to the barriers and creating inappropriate care for adults on the autism spectrum.

Several solutions are suggested to bridge the gap in providing services to individuals on the autism spectrum. First, providing educational programs for HCPs during their school years and later as professional development opportunities is strongly recommended. Service providers need to learn how to provide appropriate service and be equipped with strategies to make the service and its environment appropriate for this client group. Some strategies can be as simple as allowing enough time for the person to understand options and participate in decision-making. Reducing the time in the waiting room and directing the clients to a private room faster than usual can help reduce the risk of sensory overload. HCPs should take a strength-based approach rather than focusing on the person's deficits.

Second, HCPs need to learn skills to communicate more effectively with this client group better. Some articles suggested HCPs should receive education around accommodating alternative forms of communication such as written messa+ges to reduce communication barriers in practice settings (Blomqvist et al., 2015; Lipinski et al., 2019; Lum et al., 2014). Competent HCPs should be attentive to the needs of individuals on the autism spectrum, such as creating environments with low stimulation and allowing clients additional processing time as needed to understand services (Lipinski et al., 2019; Mason et al., 2019; Nicolaidis et al., 2013; Saqr et al., 2018; Stein Duker et al., 2019; Warfield et al., 2015). Furthermore, adults on the autism spectrum, caregivers and HCPs found strategies such as reducing wait times, strategic scheduling, providing HCP with a list of needs before the visit, using social stories and visual schedules will significantly improve the experience of health care visits (Stein Duker et al., 2019). 
Third, to reduce the access barriers, further research is needed to develop clinical guidelines focusing on improving service access. Clinical practice guidelines elated to ASD tend to focus solely on the diagnostic element of care, and its focus was primarily on the child population. Resources such as Autism Awareness Australia and Autism Canada focus on diagnosing the pediatric population with limited resources available for health care providers (Autism Canada, 2018; Www.Autismawareness.Com.Au, 2019). There are currently some helpful resources provided by the English Primary Autism Network (National Autistic Society, 2019) for HCPs to improve the appropriability of services. Further studies are needed to understand how effective these interventions can be to reduce barriers to health care for adults on the autism spectrum.

Fourth, efforts should be made to reduce stigma. Acceptability barriers result from extra personal and intrapersonal stigma experienced (Bachmann et al., 2019). Stigma is a sociocultural phenomenon of disempowering an outgroup through stereotypes and separation, using internal pressure to make decisions that are culturally permissible or superimposed by others (Corrigan, 2000). A typical example is HCPs who prefer to communicate with caregivers or other professionals rather than adults on the autistic spectrum. This act of neglect is due to the underlying presumption that the adult cannot be trusted to govern their care (Lewis, 2017; Rodgers et al., 2019). Health care providers who ask the other adults in the room to make care decisions, reaffirm stigma by marginalizing the client. It is important to recognize, call out, and relinquish this practice in health care by educating care providers about the damage it can cause. Intrapersonal stigma is also a significant barrier to access. This study demonstrated that adults on the autism spectrum often avoid seeking care because they feel they would pose an undue burden on the system. This finding illustrates the importance of validating the care needs of individuals on the autism spectrum to work towards decreasing internalized stigma.

Stigma as a barrier to health care services is not unique to the population of individuals on the autism spectrum. Progress to reduce stigma and improve appropriateness should be built on the lessons from the past. Populations such as the transgender communities, individuals that are HIV positive, individuals that are obese, and beyond have been subjected to the stigma that has affected their ability to access health care services (Drury \& Louis, 2002; Kinsler et al., 2007; Poteat et al., 2013). For example, a study in 2007 found that 1 in 4 HIV-positive residents of Los Angeles reported having experienced some type of stigma from care providers that interfered with their ability or willingness to seek necessary health supports (Kinsler et al., 2007). Frameworks have been developed and implemented to address the stigma for these communities and others, which can guide work to address the stigma that individuals on the autism spectrum experience, such as prioritized training of HCPs and empowering the stigmatized to demand respect (Brinsdon et al., 2016; Heijnders \& Van Der Meij, 2006; Nyblade et al., 2009).

As demonstrated by this paper's results, barriers to access health services by adults on the autism spectrum exist in all dimensions of Levesque's access framework (Levesque et al., 2013). The dimensions of accessibility, affordability, and approachability are valued pieces of the access puzzle. They should not be dismissed when considering how to improve the experience adults on the autism spectrum have when accessing health services. There is room for vast improvement at the policy level to improve services' accessibility, such as increasing funding for providers that deliver care that accounts for individuals' needs on the autism spectrum (Baldwin \& Costley, 2016). Improved availability of formal supports for adults on the autism spectrum can result in better health care self-efficacy and reaffirm their role in the care process (Nicolaidis et al., 2015). It can also improve the continuity of care between providers so that clients' needs can be continually met in different care settings (Henry, 2013). Two studies also suggested that providers should receive incentives to provide services that consider the needs of individuals on the autism spectrum (Tint \& Weiss, 2018; Warfield et al., 2015). The findings of this study add to the results of the study by Mason et al. (2019) in that affordability and acceptability of the services are necessary to consider to enhance access to the health care services by this population group. People on the autism spectrum need to be educated about when and how to access the services and the financial barriers such as lack of insurance coverage and incentives for providers hinder individuals on the autism spectrum from receiving services when they need them.

Other specific areas identified for future research include understanding individuals' intersectionality, such as sex and gender, when accessing the healthcare system. There is an overrepresentation of women on the autism spectrum reported in multiple studies included in this review. Additionally, there is an increased societal and academic level of attention to gender. Therefore, more research is required to understand the compounding effects of gender and ASD and how experiences can differ between populations. There is also a need for more specificity in ASD research, as ASD represents a spectrum of conditions but in health care, it is often treated with a one size fits all mentality. There is space to begin to understand how adults with various types of ASD experience access to health care services. For example, an adult with what was traditionally diagnosed as Asperger's Syndrome may access health services differently from someone diagnosed with Fragile X. Their strategies to remove barriers and 
improve access may differ. Therefore, it is necessary to understand these differences and how they may affect the implementation of accommodations within the health care setting.

\section{Limitations}

As per the inclusion criteria of this study, the search was conducted for papers published in English, limiting the generalizability of the study and reducing the diversity of sample populations. While this study sought to take a global perspective, over two-thirds of the studies referenced in this review focus on the experience of individuals on the autism spectrum in three countries: The United States of America, Canada, and the United Kingdom, further limiting the generalizability of findings. The experience of individuals on the autism spectrum in non-English speaking nations and those with fundamentally different health care systems may differ from the results reported in this review and should be investigated in future research. Conference abstracts were also excluded due to insufficient data, and studies that focused on youths transitioning into adulthood were excluded. However, the inclusion of this population may have provided experiential data around access as one begins interacting with adult health services.

Furthermore, there is a limitation around excluding studies with a sample population of individuals with an "intellectual or developmental disability," as this may have omitted pertinent information related to the specific experiences of individuals on the autism spectrum. Finally, many studies relied on gathering information through technology such as online surveys, limiting the sample's demographic to those who can access and utilize this mode of communication. Future research should consider an inclusive data collection strategy to ensure results are widely applicable.

\section{Conclusion}

This paper investigated the barriers individuals on the autism spectrum experience when accessing health care services. Results revealed that most barriers fell under the dimensions of appropriateness and acceptability of care. These results may be counter-intuitive to the instinctive spontaneous elements of affordability and availability that one may strive to improve when working to improve access. The experiences of adults on the autism spectrum demonstrate the quality of care they are receiving, and acceptance is their primary concern. Therefore, a need for improvement in these areas is evident. Some strategies to remove barriers include educating HCPs and creating an environment that accommodates the individual's needs. Efforts need to be put in place to destigmatize individuals' perceptions on the autism spectrum to counter both internalized and external stigma this population faces when accessing care. More robust research is required to increase the amount of high-quality work to develop strategies to remove barriers and improve access to health care services. Future research should also vary their sample populations to more pointedly consider the intersection of gender and ASD and explore individuals' experiences in various countries.

\section{Acknowledgements}

We thank Ms. Paola Durando, Health Sciences Librarian, who helped with refining our database search strategy.

\section{Competing Interests Statement}

The authors declare that there are no competing or potential conflicts of interest.

\section{References}

Alegria Drury, C. A., \& Louis, M. (2002). Exploring the association between body weight, stigma of obesity, and health care avoidance. Journal of the American Academy of Nurse Practitioners, 14(12), 554-561. https://doi.org/10.111/j.1745-7599.2002.tb00089.x

Autism Canada. (2018). Autism Canada. Retrieved from https://autismcanada.org/\#home-row-3

Au-Yeung, S. K., Bradley, L., Robertson, A. E., Shaw, R., Baron-Cohen, S., \& Cassidy, S. (2019). Experience of mental health diagnosis and perceived misdiagnosis in autistic, possibly autistic and non-autistic adults. Autism, 23(6), 1508-1518. https://doi.org/10.1177/1362361318818167

Bachmann, C. J., Gerste, B., \& Hoffmann, F. (2018). Diagnoses of autism spectrum disorders in Germany: time trends in administrative prevalence and diagnostic stability. Autism, 22(3), 283-290. https://doi.org/10.1177/1362361316673977

Bachmann, C. J., Höfer, J., Kamp-Becker, I., Küpper, C., Poustka, L., Roepke, S., ... \& Hoffmann, F. (2019). Internalised stigma in adults with autism: a German multi-center survey. Psychiatry research, 276, 94-99. https://doi.org/10.1016/j.psychres.2019.04.023

Baldwin, S., \& Costley, D. (2016). The experiences and needs of female adults with high-functioning autism 
spectrum disorder. Autism, 20(4), 483-495. https://doi.org/10.1177/1362361315590805

Baldwin, S., Costley, D., \& Warren, A. (2014). Employment activities and experiences of adults with high-functioning autism and Asperger's disorder. Journal of autism and developmental disorders, 44(10), 2440-2449. https://doi.org/10.1007/s10803-014-2112-z

Blomqvist, M., Bejerot, S., \& Dahllöf, G. (2015). A cross-sectional study on oral health and dental care in intellectually able adults with autism spectrum disorder. BMC Oral Health, 15(1), 1-8. https://doi.org/10.1186/s12903-015-0065-z

Bogenschutz, M. (2014). " We Find a Way": Challenges and Facilitators for Health Care Access Among Immigrants and Refugees With Intellectual and Developmental Disabilities. Medical Care, S64-S70. https://doi.org/10.1097/MLR.0000000000000140

Brinsdon, A., Abel, G., \& Desrosiers, J. (2017). "I'm taking control”: how people living with HIV/AIDS manage stigma in health interactions. AIDS care, 29(2), 185-188. https://doi.org/10.1080/09540121.2016.1204420

Bruder, M. B., Kerins, G., Mazzarella, C., Sims, J., \& Stein, N. (2012). Brief report: The medical care of adults with autism spectrum disorders: Identifying the needs. Journal of autism and developmental disorders, 42(11), 2498-2504. https://doi.org/10.1007/s10803-012-1496-x

Camm-Crosbie, L., Bradley, L., Shaw, R., Baron-Cohen, S., \& Cassidy, S. (2019). 'People like me don't get support': Autistic adults' experiences of support and treatment for mental health difficulties, self-injury and suicidality. Autism, 23(6), 1431-1441. https://doi.org/10.1177/1362361318816053

Corrigan, P. W. (2000). Mental health stigma as social attribution: Implications for research methods and attitude change. Clinical psychology: science and practice, 7(1), 48. https://doi.org/10.1093/clipsy.7.1.48

Crane, L., Batty, R., Adeyinka, H., Goddard, L., Henry, L. A., \& Hill, E. L. (2018). Autism diagnosis in the United Kingdom: Perspectives of autistic adults, parents and professionals. Journal of autism and developmental disorders, 48(11), 3761-3772. https://doi.org/10.1007/s10803-018-3639-1

Croen, L. A., Zerbo, O., Qian, Y., Massolo, M. L., Rich, S., Sidney, S., \& Kripke, C. (2015). The health status of adults on the autism spectrum. Autism, 19(7), 814-823. https://doi.org/10.1177/1362361315577517

Diallo, F. B., Fombonne, É., Kisely, S., Rochette, L., Vasiliadis, H. M., Vanasse, A., ... \& Lesage, A. (2018). Prevalence and correlates of autism spectrum disorders in Quebec: Prévalence et corrélats des troubles du spectre de l'autisme au Québec. The Canadian Journal of Psychiatry, 63(4), 231-239. https://doi.org/10.1177/0706743717737031

Dudley, K. M., Klinger, M. R., Meyer, A., Powell, P., \& Klinger, L. G. (2019). Understanding service usage and needs for adults with ASD: The importance of living situation. Journal of Autism and Developmental Disorders, 49(2), 556-568. https://doi.org/10.1007/s10803-018-3729-0

Fortuna, R. J., Robinson, L., Smith, T. H., Meccarello, J., Bullen, B., Nobis, K., \& Davidson, P. W. (2016). Health conditions and functional status in adults with autism: A cross-sectional evaluation. Journal of General Internal Medicine, 31(1), 77-84. https://doi.org/10.1007/s11606-015-3509-x

Heijnders, M., \& Van Der Meij, S. (2006). The fight against stigma: an overview of stigma-reduction strategies and interventions. Psychology, health \& medicine, 11(3), 353-363. https://doi.org/10.1080/13548500600595327

Henry, A. R. (2013). Barriers to accessing support services in employment and health care for adults with autism spectrum disorders: A qualitative study. University of Southern California.

Hewitt, A. S., Stancliffe, R. J., Sirek, A. J., Hall-Lande, J., Taub, S., Engler, J., ... \& Moseley, C. R. (2012). Characteristics of adults with autism spectrum disorder who use adult developmental disability services: Results from 25 US states. Research in Autism Spectrum Disorders, 6(2), 741-751. https://doi.org/10.1016/j.rasd.2011.10.007

Hirvikoski, T., Mittendorfer-Rutz, E., Boman, M., Larsson, H., Lichtenstein, P., \& Bölte, S. (2016). Premature mortality in autism spectrum disorder. The British Journal of Psychiatry, 208(3), 232-238. https://doi.org/10.1192/bjp.bp.114.160192

Jensen, C. M., Steinhausen, H. C., \& Lauritsen, M. B. (2014). Time trends over 16 years in incidence-rates of autism spectrum disorders across the lifespan based on nationwide Danish register data. Journal of autism and developmental disorders, 44(8), 1808-1818. https://doi.org/10.1007/s10803-014-2053-6

Jokiranta-Olkoniemi, E., Gyllenberg, D., Sucksdorff, D., Suominen, A., Kronström, K., Chudal, R., \& Sourander, 
A. (2021). Risk for premature mortality and intentional self-harm in autism spectrum disorders. Journal of autism and developmental disorders, 51(9), 3098-3108. https://doi.org/10.1007/s10803-020-04768-x

Kinsler, J. J., Wong, M. D., Sayles, J. N., Davis, C., \& Cunningham, W. E. (2007). The effect of perceived stigma from a health care provider on access to care among a low-income HIV-positive population. AIDS patient care and STDs, 21(8), 584-592. https://doi.org/10.1089/apc.2006.0202

Lai, J. K., \& Weiss, J. A. (2017). Priority service needs and receipt across the lifespan for individuals with autism spectrum disorder. Autism Research, 10(8), 1436-1447. https://doi.org/10.1002/aur.1786

Levesque, J. F., Harris, M. F., \& Russell, G. (2013). Patient-centred access to health care: conceptualising access at the interface of health systems and populations. International journal for equity in health, 12(1), 1-9. https://doi.org/10.1186/1475-9276-12-18

Lewis, L. F. (2017). A mixed methods study of barriers to formal diagnosis of autism spectrum disorder in adults. Journal of autism and developmental disorders, 47(8), 2410-2424. https://doi.org/10.1007/s10803-017-3168-3

Lipinski, S., Blanke, E. S., Suenkel, U., \& Dziobek, I. (2019). Outpatient psychotherapy for adults with high-functioning autism spectrum condition: utilization, treatment satisfaction, and preferred modifications. Journal of autism and developmental disorders, 49(3), 1154-1168. https://doi.org/10.1007/s10803-018-3797-1

Lum, M., Garnett, M., \& O'Connor, E. (2014). Health communication: A pilot study comparing perceptions of women with and without high functioning autism spectrum disorder. Research in Autism Spectrum Disorders, 8(12), 1713-1721. https://doi.org/10.1016/j.rasd.2014.09.009

Maloret, P., \& Scott, T. (2018). Don't ask me what's the matter, ask me what matters: Acute mental health facility experiences of people living with autism spectrum conditions. Journal of psychiatric and mental health nursing, 25(1), 49-59. https://doi.org/10.1111/jpm.12438

Mason, D., Ingham, B., Urbanowicz, A., Michael, C., Birtles, H., Woodbury-Smith, M., ... \& Parr, J. R. (2019). A systematic review of what barriers and facilitators prevent and enable physical healthcare services access for autistic adults. Journal of autism and developmental disorders, 49(8), 3387-3400. https://doi.org/10.1007/s10803-019-04049-2

Mattila, M. L., Hurtig, T., Haapsamo, H., Jussila, K., Kuusikko-Gauffin, S., Kielinen, M., ... \& Moilanen, I. (2010). Comorbid psychiatric disorders associated with Asperger syndrome/high-functioning autism: a community-and clinic-based study. Journal of autism and developmental disorders, 40(9), 1080-1093. https://doi.org/10.1007/s10803-010-0958-2

National Autistic Society. (2019). Autism and Mental Health. Retrieved from learn.autism.org.uk

Nicolaidis, C., Raymaker, D. M., Ashkenazy, E., McDonald, K. E., Dern, S., Baggs, A. E., ... \& Boisclair, W. C. (2015). "Respect the way I need to communicate with you": Healthcare experiences of adults on the autism spectrum. Autism, 19(7), 824-831. https://doi.org/10.1177/1362361315576221

Nicolaidis, C., Raymaker, D., McDonald, K., Dern, S., Boisclair, W. C., Ashkenazy, E., \& Baggs, A. (2013). Comparison of healthcare experiences in autistic and non-autistic adults: a cross-sectional online survey facilitated by an academic-community partnership. Journal of general internal medicine, 28(6), 761-769. https://doi.org/10.1007/s11606-012-2262-7

Nord, D. K., Stancliffe, R. J., Nye-Lengerman, K., \& Hewitt, A. S. (2016). Employment in the community for people with and without autism: A comparative analysis. Research in Autism Spectrum Disorders, 24, 11-16. https://doi.org/10.1016/j.rasd.2015.12.013

Nyblade, L., Stangl, A., Weiss, E., \& Ashburn, K. (2009). Combating HIV stigma in health care settings: what works?. Journal of the International AIDS Society, 12(1), 1-7. https://doi.org/10.1186/1758-2652-12-15

Poteat, T., German, D., \& Kerrigan, D. (2013). Managing uncertainty: a grounded theory of stigma in transgender $\begin{array}{llll}\text { health care encounters. Social science \& medicine, } 84, & 22-29 .\end{array}$ https://doi.org/10.1016/j.socscimed.2013.02.019

Raymaker, D. M., McDonald, K. E., Ashkenazy, E., Gerrity, M., Baggs, A. M., Kripke, C., ... \& Nicolaidis, C. (2017). Barriers to healthcare: Instrument development and comparison between autistic adults and adults with and without other disabilities. Autism, 21(8), 972-984. https://doi.org/10.1177/1362361316661261 
Rodgers, J., Herrema, R., Garland, D., Osborne, M., Cooper, R., Heslop, P., \& Freeston, M. (2019). Uncertain futures: Reporting the experiences and worries of autistic adults and possible implications for social work practice. The British Journal of Social Work, 49(7), 1817-1836. https://doi.org/10.1093/bjsw/bcy117

Ross, L. E., Vigod, S., Wishart, J., Waese, M., Spence, J. D., Oliver, J., ... \& Shields, R. (2015). Barriers and facilitators to primary care for people with mental health and/or substance use issues: a qualitative study. BMC family practice, 16(1), 1-13. https://doi.org/10.1186/s12875-015-0353-3

Saqr, Y., Braun, E., Porter, K., Barnette, D., \& Hanks, C. (2018). Addressing medical needs of adolescents and adults with autism spectrum disorders in a primary care setting. Autism, 22(1), 51-61. https://doi.org/10.1177/1362361317709970

Schendel, D. E., \& Thorsteinsson, E. (2018). Cumulative incidence of autism into adulthood for birth cohorts in Denmark, 1980-2012. Jama, 320(17), 1811-1813. https://doi.org/10.1001/jama.2018.11328

Stein Duker, L. I., Sadie Kim, H. K., Pomponio, A., Mosqueda, L., \& Pfeiffer, B. (2019). Examining primary care health encounters for adults with autism spectrum disorder. The American Journal of Occupational Therapy, 73(5), 7305185030p1-7305185030p11. https://doi.org/10.5014/ajot.2019.037226

Tint, A., \& Weiss, J. A. (2018). A qualitative study of the service experiences of women with autism spectrum disorder. Autism, 22(8), 928-937. https://doi.org/10.1177/1362361317702561

van Asselt-Goverts, A. E., Embregts, P. J. C. M., Hendriks, A. H. C., Wegman, K. M., \& Teunisse, J. P. (2015). Do social networks differ? Comparison of the social networks of people with intellectual disabilities, people with autism spectrum disorders and other people living in the community. Journal of Autism and Developmental Disorders, 45(5), 1191-1203. https://doi.org/10.1007/s10803-014-2279-3

Van Hees, V., Moyson, T., \& Roeyers, H. (2015). Higher education experiences of students with autism spectrum disorder: Challenges, benefits and support needs. Journal of autism and developmental disorders, 45(6), 1673-1688. https://doi.org/10.1007/s10803-014-2324-2

Vogan, V., Lake, J. K., Tint, A., Weiss, J. A., \& Lunsky, Y. (2017). Tracking health care service use and the experiences of adults with autism spectrum disorder without intellectual disability: A longitudinal study of service rates, barriers and satisfaction. Disability and Health Journal, 10(2), 264-270. https://doi.org/10.1016/j.dhjo.2016.11.002

Vohra, R., Madhavan, S., \& Sambamoorthi, U. (2016). Emergency department use among adults with autism spectrum disorders (ASD). Journal of autism and developmental disorders, 46(4), 1441-1454. https://doi.org/10.1007/s10803-015-2692-2

Warfield, M. E., Crossman, M. K., Delahaye, J., Der Weerd, E., \& Kuhlthau, K. A. (2015). Physician perspectives on providing primary medical care to adults with autism spectrum disorders (ASD). Journal of autism and developmental disorders, 45(7), 2209-2217. https://doi.org/10.1007/s10803-015-2386-9

World Health Organization. (2017). Retrieved from Human rights and health. https://www.who.int/news-room/fact-sheets/detail/human-rights-and-health

World Health Organization. (2018). Retrieved from Autism spectrum disorders. https://www.who.int/news-room/fact-sheets/detail/autism-spectrum-disorders?fbclid=IwAR113J4HiK1 uy65 FSMmf8SnDuSB1KcwRVh5PRaWiCCE-4xZ_DpG9Dum80Mw

www.autismawareness.com.au. (2019). www.autismawareness.com.au

\section{Copyrights}

Copyright for this article is retained by the author(s), with first publication rights granted to the journal.

This is an open-access article distributed under the terms and conditions of the Creative Commons Attribution license (http://creativecommons.org/licenses/by/4.0/). 